\title{
Pattern of Ovarian Follicular Development and Steroid Hormone Concentrations during Estrous Cycle of Lohi Sheep
}

\author{
Muhammad Younis ${ }^{1}$, Muhammad Irfan-ur-Rehman Khan ${ }^{1 *}$, Mustansar Abbas ${ }^{1}$, \\ Ali Murtaza ${ }^{1}$, Imran Mohsin ${ }^{2}$, Muhammad Shahzad ${ }^{3}$ and Muhammad Zahid Tahir ${ }^{1}$
}

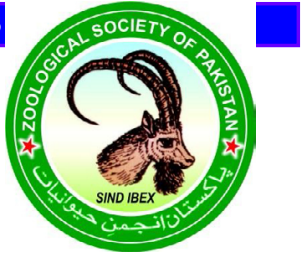

${ }^{1}$ Department of Theriogenology, University of Veterinary and Animal Sciences, Lahore-54000

${ }^{2}$ Department of Livestock Production, University of Veterinary and Animal Sciences, Lahore-54000

${ }^{3}$ Nuclear Institute for Agriculture and Biology, Jhang Road, Faisalabad-38000

\begin{abstract}
A B S T RA C T
The objective of the study was to determine ovarian follicular development and steroid hormones concentrations during estrous cycle of Lohi sheep. Ovaries of nine Lohi ewes were monitored for two consecutive estrous cycles using B-mode trans-rectal ultrasonography during the breeding season (SepNov 2018). Plasma progesterone and estradiol-17 $\beta$ concentrations were determined throughout the cycle using radioimmunoassay. The average length of the estrous cycle in Lohi sheep was 17.0 \pm 0.1 days and follicular and luteal phases were $4.6 \pm 0.2$ and $11.3 \pm 0.2$ days long, respectively. Estrous cycles had either three or four follicular waves; 3 -wave cycles were more frequent than 4 -waves $(87 \mathrm{vs.13 \%}$; $p \leq 0.05$, respectively). In 3-wave cycles $(\mathrm{n}=14)$, follicles $(\leq 3 \mathrm{~mm})$ emerged on Days $0.7,5.2$ and 10.5. In 4-wave cycles $(\mathrm{n}=2)$, follicles emerged on Days $0.1,4,8.5$, and 11.5. The maximum diameter of preovulatory follicle and corpus luteum was $5.4 \pm 0.3$ and $10.4 \pm 0.3 \mathrm{~mm}$, respectively. Regardless of the wave pattern, single ovulation occurred in each cycle. CL was first detectable on Day $4.0 \pm 0.1$, it reached maximum diameter on Day 9.0 \pm 0.1 and luteolysis began on Day $12.2 \pm 0.2$ of the cycle. Peak estradiol-17 concentration was observed $48 \mathrm{~h}$ before ovulation and correlated with the diameter of the preovulatory follicle $(\mathrm{r}=0.84 ; p<0.05)$. Plasma progesterone concentration was maximum on Day $9 \pm 0.1$ and coincided with the diameter of CL throughout the cycle $(\mathrm{r}=0.93 ; p<0.05)$. In conclusion, most of the cycles in Lohi sheep have 3 -waves and are mono-ovulatory in nature.
\end{abstract}

\begin{tabular}{l} 
Article Information \\
Received 04 November 2019 \\
Revised 22 February 2020 \\
Accepted 04 March 2020 \\
Available online 26 March 2021 \\
Authors' Contribution \\
\hline MY and MIRK designed and analyzed \\
the study and wrote the manuscript. \\
AM helped in the execution of the \\
study. MA did the statistical analyses. \\
IM supervised the feeding and \\
management of sheep. MS performed \\
the hormonal analyses. MZT and all \\
other authors critically reviewed the \\
manuscript. \\
Key words \\
Follicular dynamics, Estradiol-17ß, \\
Progesterone, Lohi sheep, Estrous \\
cycle
\end{tabular}

\section{INTRODUCTION}

L ivestock is an integral part of agriculture based Asian economies and its share in agricultural gross domestic production (GDP) of various countries varies from 13 to $60 \%$. In Pakistan, the livestock contributes $11 \%$ of the national GDP (Economic Survey of Pakistan, 20182019). Even though livestock sector remained largely disorganized, but it has huge potential to provide food security and livelihood to masses.

In Pakistan, the sheep population is 30.9 million heads (Economic Survey of Pakistan, 2018-2019) and is a source of livelihood for rural people. Among several sheep breeds, Lohi sheep, found in central Punjab, is a medium-size polled breed having white body color, dense, coarse and long-stapled fleece, and large leafy ears. Lohi sheep are also known as "Parkanni" due to an appendage on its external ears.

\footnotetext{
* Corresponding author: irfan.khan@uvas.edu.pk 0030-9923/2021/0003-0987\$ 9.00/0

Copyright 2021 Zoological Society of Pakistan
}

Lohi is mainly reared for meat and wool production (Khan, 2002). Lohi rams and ewes weigh $\sim 62$ and $45 \mathrm{~kg}$, respectively (Babar, 1994). Under field conditions, Lohi sheep are maintained on grazing and are naturally bred during February-March or September-October. Studies conducted at livestock experimental stations of Punjab indicate that the average age of Lohi ewes at first service is $615.2 \pm 5.5$ days and their average gestational length is152.5 \pm 0.1 days (Ahmad et al., 2001; Babar et al., 2004). The lambing and fecundity rates of Lohi sheep are $0.80 \pm 0.11$ and $1.45 \pm 01$, respectively (Khan, 2002). Lohi lambs achieve $\sim 31-36 \mathrm{~kg}$ weight by the age of nine months (Ahmad et al., 2001). Hence, the characteristics of Lohi sheep appear to be breed specific.

Previous studies indicate that ultrasonography is a useful, non-invasive and reliable tool for understanding the ovarian follicular dynamics in cow (Sirois and Fortune, 1988), sheep (Ginther et al., 1995) and goat (Murtaza et al., 2019). Knowledge about hormonal changes and ovarian follicular development during the estrous cycle of domestic animals has been used for developing 
synchronization protocols and for improving the outcomes of such interventions (Wildeus, 2000; Boscos et al., 2002; Titi et al., 2010). Despite the superior genetic make-up of the native sheep breeds, limited knowledge of reproductive cyclicity impedes the exploitation of their genetic potential. As a result, modern reproductive technologies such as estorus synchronization, artificial insemination, multiple ovulations and embryo transfer have limited scope for sustained sheep production and genetic improvement. Therefore, the objective of the present study was to characterize ovarian follicular dynamics and plasma concentrations of estradiol-17 $\beta$ and progesterone throughout the estrous cycle in Lohi sheep.

\section{MATERIALS AND METHODS}

\section{Geographical location, experimental animals, and estrous synchronization}

Nine cyclic multiparous Lohi sheep (Age: $3 \pm 0.2$ years; body condition score: $2.8 \pm 0.2$ ) kept at Small Ruminant Training and Research Centre, Pattoki, Kasur $\left(31^{\circ} 03^{\prime} 29.0^{\prime \prime} \mathrm{N} 73^{\circ} 52^{\prime} 42.9^{\prime \prime} \mathrm{E}\right)$ were synchronized during the breeding season (September-November, 2018) by administering single dose of prostaglandin analogue (cloprostenol sodium; Cyclomate ${ }^{\circledR}, 263 \mathrm{mcg}$, i.m., Star laboratories, Pakistan) after detecting the carpus luteum on ovary using B-mode ultrasound with $7.5 \mathrm{MHz}$ trans-rectal transducer (HS-1500 ${ }^{\circledR}$, Honda, Tokyo, Japan). All animals were kept in free stalls, and given seasonal green fodder (Sorghum 3-4kg) along with silage (maize and barley: $2-3 \mathrm{~kg}$ ), concentrate (300g; containing soybean meal, corn gluten, corn grain, canola meal, and wheat bran) daily. All animals had an access to clean water ad libitum. All procedures were approved by the Animal Care and Ethical Review Committee of the University of Veterinary and Animal Sciences, Lahore-Pakistan.

Ultrasound examination of ovaries and follicular dynamics

Ovarian changes in ewes $(n=9)$ were monitored daily by a single operator for two consecutive estrous cycles following $\mathrm{PGF}_{2 \alpha}$ induced ovulation through real-time B-mode ultrasound (HS-1500 ${ }^{\circledR}$, Honda, Tokyo, Japan). Briefly, linear transducer $(7.5 \mathrm{MHz})$ was inserted into the rectum after removing fecal pellets using lubricated index finger. Urinary bladder (anechoic) was used as landmark and ovaries were located cranial to the bladder by gently rotating the probe either in a clockwise or anti-clockwise direction. The diameter of antral follicles (anechoic) and corpora lutea (hypoechoic) were measured, and their relative positions on ovary were mapped daily. Ovarian changes were compared using the identity method based on previous day's examination (Ginther et al., 2004).
For each estrous cycle, follicular waves, the day of wave emergence, inter-ovulatory interval (IOI), inter-wave interval (IWI), ovulation rate, and luteal dynamics were estimated. For each follicular wave, follicles ( $\geq 3 \mathrm{~mm}$ ) at wave emergence, diameters of the first largest (F1) and sub-ordinate follicles (SF), the day of largest follicle diameter, the growth rate of $F 1$, the day of F1 selection, and phases of $\mathrm{F} 1$ growth and dominance were observed.

The interval between two successive ovulations was defined as inter-ovulatory interval (IOI). Interwave interval (IWI) was defined as the time between the emergences of two successive waves. The wave emergence (WE) was characterized by the sudden appearance of a cohort of follicles ( $\geq 3 \mathrm{~mm}$ ) of which one or two follicles reached a size $\geq 5 \mathrm{~mm}$ within next $48 \mathrm{~h}$ (Neal et al., 1993). The day of F1 selection was defined as the day when single antral follicle (F1) deviated from the remaining cohort of follicles in diameter (Campbell et al., 1995). The day at which a follicle achieved the largest diameter and did not increase subsequently was defined as the day of largest follicle's diameter. The largest dominant follicle prior to ovulation was defined as a preovulatory follicle. Sudden disappearance of the previously detected largest follicle on the subsequent ovarian ultrasound scan was defined as the day of ovulation (Day 0). The luteolysis was defined as the first day when there was a substantial decrease in the diameter of CL relative to its previous diameter. The duration from luteolysis till ovulation was defined as the follicular phase. The duration from ovulation till luteolysis was defined as the luteal phase. The early-luteal phase was the period from ovulation until the time when CL reached its maximum size. The mid-luteal phase was the period when CL diameter remained constant until the initiation of luteolysis (Murtaza et al., 2019).

\section{Blood collection and hormones analyses}

Blood samples from four ewes were obtained daily via jugular venipuncture $(5 \mathrm{ml}$; BD Vacutainer $\AA$, USA) for a complete estrous cycle. Plasma was obtained by centrifuging the blood at $1200 \times \mathrm{g}$ for $13 \mathrm{~min}$, and stored at $-20^{\circ} \mathrm{C}$ till further analysis. The plasma concentrations of progesterone and estradiol-17 $\beta$ were determined in duplicates by solidphase Radioimmunoassay kits (RIA; Immunotech ${ }^{\circledR}$, Beckman coulter, Czech Republic) using ${ }^{125}$ I-labelled tracer as describe previously (Murtaza et al., 2019). The analytical sensitivities for progesterone and estradiol-17 $\beta$ assays were $0.03 \mathrm{ng} / \mathrm{ml}$ and $9.58 \mathrm{pg} / \mathrm{ml}$, respectively. The inter-assay coefficient of variation (CV) for progesterone and estradiol$17 \beta$ were $9.8 \%$ and $12.7 \%$, respectively.

\section{Statistical analyses}

The quantitative data were expressed as mean \pm SEM 
and analyzed for normal distribution using the ShapiroWilk test. The mean \pm SEM of follicular diameter, wave emergence, the growth rate of F1, the day of selection of $\mathrm{F} 1$, growth and dominance phase of F1, and IWI within 3 -wave cycles were compared through one way analysis of variance (ANOVA). Differences among waves were determined through Tukey's Post-hoc test. Pearson's Correlation Coefficient was used to determine the correlations between plasma progesterone concentration and CL diameter as well as between estradiol-17 $\beta$ and preovulatory follicle during the follicular phase. For all statistical analyses, $P$-value $\leq 0.05$ was considered significant. Data were analyzed using statistical software (SPSS, version 20.0, IBM Corp, Armonk, NY).

\section{RESULTS}

\section{Follicular and luteal dynamics during estrous cycle}

In Lohi sheep, all the observed estrous cycles $(n=16)$ were monovular in nature and had a mean inter-ovulatory interval (IOI) of $17.5 \pm 0.5$ days. Overall, the lengths of follicular and luteal phases were $4.5 \pm 0.2$ and $11.3 \pm 0.2$ days, respectively. Three wave follicular pattern was observed in eighty-seven percent of cycles (14/16) while remaining cycles $(13 \% ; 2 / 16)$ had 4 -wave pattern. In 3-wave cycles, follicular waves emerged on Days 0.7, 5.2 and 10.5 following ovulation (Day 0). In 4-wave cycles follicles emerged on Days 0.1, 4.0, 8.5, and 11.5 (Fig. 1). The average day of selection of dominant antral follicle (F1) in 3- or 4 -wave cycles was $1.6 \pm 0.2 \mathrm{~d}$ after wave emergence. The average growth rate of F1 in 3- or 4-wave cycles was $0.6 \pm 0.1 \mathrm{~mm} /$ day.

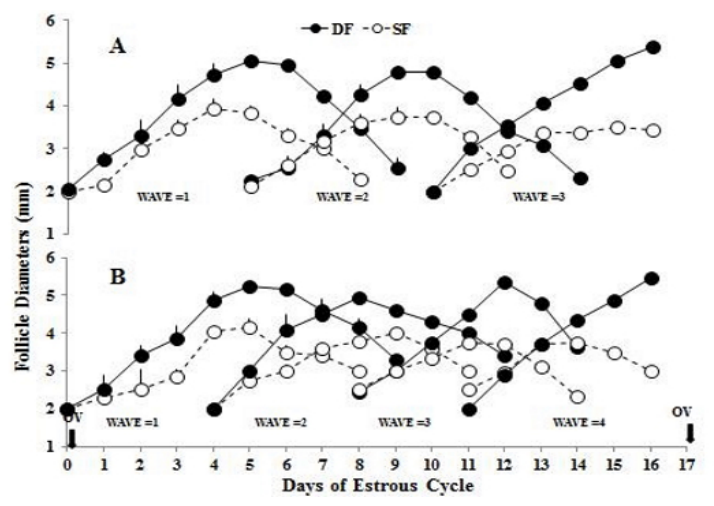

Fig. 1. Follicular development of three $(\mathrm{n}=16$; A) and four-wave $(\mathrm{n}=2$; B) cycles in Lohi sheep. Diameters (mean $\pm \mathrm{SEM}$ ) of the largest (F1) and subordinate (SF) follicles were monitored daily for two consecutive ovulations via transrectal ultrasonography. The frequency of 3-wave cycles was relatively greater $(p<0.05)$ than the 4 -wave cycles i.e., $87 \%$ vs. $13 \%$, respectively.
Within 3-wave cycles, both the dominance and plateau phases of F1 were longer $(p<0.05)$ for $3^{\text {rd }}$ wave than subsequent waves, and a similar trend was observed within 4-wave cycles. The regression phase of F1 in each wave of the 3-wave cycle did not differ $(p<0.05$; Table I). The diameter of F1 differed in each wave of 3 -wave cycles $(p<0.05)$. Regardless of 3- or 4-wave cycles, pre-ovulatory follicles achieved maximum diameter on day $16.1 \pm 0.2$. The diameter of sub-ordinate follicles (SF) and the day of maximum F1 diameter of each wave of 3- or 4- cycles are shown in (Table I). Overall, the interval between ovulatory and first wave was longer in 3-wave cycles $(p<0.05$; Table I) and a similar trend was observed within 4 -wave cycles.

Regardless of the follicular wave pattern, CL was first visible on Day 4 post-ovulation (mean diameter: $5.7 \pm 0.3 \mathrm{~mm}$ ). Thereafter, the diameter of CL increased gradually (growth phase) and attained a maximum diameter by Day $9.0 \pm 0.1(10.4 \pm 0.3 \mathrm{~mm})$, and persisted from Day 9 to 12 (plateau phase) of the cycle. On average, the luteolysis began on Day $12.2 \pm 0.2$ of the cycle. Of all the observed cycles, $25 \%$ had a CL with an anechoic central luteal cavity which disappeared by Day $9.2 \pm 0.4$ of the cycle (Fig. 2).

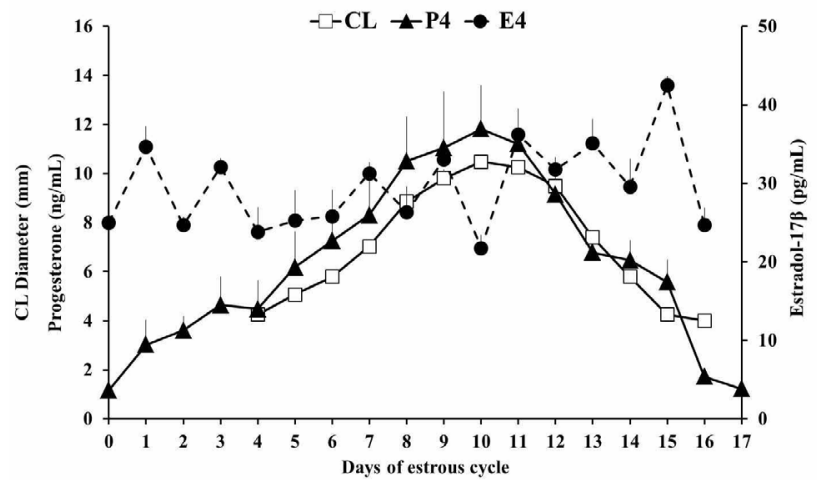

Fig. 2. Changes (mean \pm SEM) in diameter of corpus luteum, plasma concentrations of progesterone (P4; $n=4)$ and estradiol-17 $\beta(E 2 ; n=4)$. The CL became visible by Day 4, reaching a plateau on Day $9.0 \pm 0.1$ and luteolysis began by Day $12.2 \pm 0.2$ after the ovulation. The CL diameter was directly associated with the plasma progesterone concentration during the cycle $(\mathrm{r}=0.93$; $p<0.05$ ). Multiple low peaks of plasma E2 during the luteal phase (Days 1-14) and a preovulatory peak was observed during the follicular phase (Days 14-15). Arrow indicates the ovulation.

Changes in estradiol-17 $\beta$ and progesterone concentrations

The diameter of preovulatory follicle averaged $5.4 \pm 0.3 \mathrm{~mm}$. The ovulatory follicles emerged $6.5 \pm 0.2$ day prior to ovulation. The maximum plasma concentration of 
Table I. Comparison of 3- and 4-wave follicular pattern during the estrous cycle of Lohi sheep.

\begin{tabular}{|c|c|c|c|c|c|c|c|}
\hline \multirow[t]{2}{*}{ Parameters } & \multicolumn{3}{|c|}{ 3-wave cycle $(n=14)$} & \multicolumn{4}{|c|}{ 4-wave cycle $(n=2)$} \\
\hline & W1 & W2 & $\mathbf{W}_{3}$ & W1 & W2 & W3 & $\mathbf{W}_{4}$ \\
\hline Day of wave emergence & $0.7 \pm 0.1$ & $5.2 \pm 0.2$ & $10.5 \pm 0.2$ & $0.1 \pm 1$ & $4 \pm 1$ & $8.5 \pm 0.5$ & $11.5 \pm 0.5$ \\
\hline No. of follicles at WE & $6.0 \pm 0.2$ & $5.5 \pm 05$ & $5.7 \pm 0.3$ & $5.5 \pm 0.1$ & $6 \pm 0.3$ & $6 \pm 0$ & $6.5 \pm 0.1$ \\
\hline Day of selection F1 after WE & $1.8 \pm 0.2$ & $1.5 \pm 0.2$ & $1.6 \pm 0.1$ & $1.5 \pm 0.1$ & $1.5 \pm 0.1$ & $1.5 \pm 0.1$ & $2 \pm 0.2$ \\
\hline Growth rate of F1 (mm/d) & $0.6 \pm 0.0$ & $0.6 \pm 0.1$ & $0.7 \pm 0.0$ & $0.5 \pm 0.1$ & $0.6 \pm 0.1$ & $0.6 \pm 0.0$ & $0.6 \pm 0.0$ \\
\hline Growth phase of F1 (d) & $4.3 \pm 0.6$ & $4 \pm 0.4$ & $4.5 \pm 0.3$ & $3.5 \pm 0.4$ & $4 \pm 0.3$ & $3.5 \pm 0.3$ & $4 \pm 0.3$ \\
\hline Dominance phase of F1 (d) & $6 \pm 0.2^{\mathrm{a}}$ & $6 \pm 0.3^{\mathrm{a}}$ & $6.7 \pm 0.3^{b}$ & $3.5 \pm 0.1$ & $4.5 \pm 0.1$ & $4.5 \pm 0.1$ & $5.5 \pm 0.1$ \\
\hline Plateau phase of F1 (d) & $2 \pm 0.2^{\mathrm{a}}$ & $2 \pm 0.2^{\mathrm{a}}$ & $2.7 \pm 0.1^{\mathrm{b}}$ & $2 \pm 0$ & $2.5 \pm 0.2$ & $1.5 \pm 0$ & $3 \pm 0.1$ \\
\hline Regression phase of F1 (d) & $3.6 \pm 0.4$ & $4 \pm 0.3$ & - & $3.5 \pm 0.1$ & $4 \pm 0$ & $2.5 \pm 0.1$ & - \\
\hline Diameter of largest follicle (F1) & $5.1 \pm 0.4^{\mathrm{a}}$ & $4.8 \pm 0^{\mathrm{b}}$ & $5.4 \pm 0.3^{\mathrm{c}}$ & $5.2 \pm 0.2$ & $4.9 \pm 0.1$ & $5.3 \pm 0.1$ & $5.4 \pm 0.1$ \\
\hline Diameter of $1^{\text {st }}$ sub follicle & $4.0 \pm 0.1$ & $4.1 \pm 0.1$ & $4.0 \pm 0$ & $4.2 \pm 0$ & $4.1 \pm 0$ & $3.7 \pm 0.1$ & $3.7 \pm 0.2$ \\
\hline Average of max. F1diameter (d) & $5.9 \pm 0.3$ & $9.8 \pm 0.2$ & $16.1 \pm 0.2$ & $5.5 \pm 0.3$ & $8.5 \pm 0.5$ & $12.5 \pm 0.6$ & $16 . \pm 0.1$ \\
\hline \multirow[t]{2}{*}{ Inter wave interval (IWI; d) } & W1-W2 & W2-W3 & W3-W1 & W1-W2 & W2-W3 & W3-W4 & W4-W1 \\
\hline & $3.5 \pm 0.2^{\mathrm{a}}$ & $3.6 \pm 0.3^{\mathrm{a}}$ & $7.4 \pm 0.2^{\mathrm{b}}$ & $3.5 \pm 0.5$ & $3.5 \pm 0.5$ & $3 \pm 0$ & $6.5 \pm 0.5$ \\
\hline
\end{tabular}

${ }^{a b c}$ denote differences within 3- wave cycle. Values with similar superscripts within a row are not different $(p>0.05)$. d, days.

Table II. Characteristics of 3- and 4-wave estrous cycles in Lohi sheep.

\begin{tabular}{lll}
\hline Parameters & 3-wave (n=14) & 4-wave (n=2) \\
\hline Interovulatory interval (IOI; d) & $17.0 \pm 0.1$ & $17.5 \pm 0.5$ \\
Follicular phase (d) & $4.6 \pm 0.2$ & $4.5 \pm 0.1$ \\
Luteal phase (d) & $11.3 \pm 0.2$ & $11.0 \pm 0$ \\
Ovulation rate & $1 \pm 0$ & $1 \pm 0$ \\
Selection of F1 of each wave after WE (d) & $1.6 \pm 0.5$ & $1.6 \pm 0.7$ \\
Mean day WE of ovulatory follicle (d) & $10.4 \pm 0.2$ & $11.5 \pm 0.5$ \\
Day of max. preovulatory follicle (d) & $16.1 \pm 0.2$ & $16 . \pm 0.1$ \\
Mean max. progesterone concentration (ng/ml) & $11.8 \pm 1.7$ & $===$ \\
Day of max. progesterone concentration (d) & $9 \pm 0.1$ & $==$ \\
CL diameter (mm) & & $4.8 \pm 0.8$ \\
Early luteal phase (Day 0-6) & $5.0 \pm 0.2$ & $10.4 \pm 0.5$ \\
Mid-late luteal phase (Day 7-11) & $10.7 \pm 0.2$ & $6.4 \pm 0.4$ \\
Follicular phase (Day 12-17) & $5.3 \pm 0.2$ & $===$ \\
Progesterone concentration (ng/ml) & & $===$ \\
Early luteal phase (Day 0-6) & & $===$ \\
Mid-late luteal phase (Day 7-11) & $4.3 \pm 1.0$ & $10.3 \pm 1.7$ \\
Follicular phase (Day 12-17) & $4.3 \pm 0.4$ & \\
\hline
\end{tabular}

estradiol-17 $(42.5 \pm 2.6 \mathrm{pg} / \mathrm{ml})$ was observed $48 \mathrm{~h}$ before ovulation and it decreased to $21.6 \pm 1.5 \mathrm{pg} / \mathrm{ml}$ within $24 \mathrm{~h}$ of ovulation. Throughout the estrous cycle, plasma profile of estradiol-17 $\beta$ fluctuated and did not show distinct pattern. However, estradiol-17 $\beta$ correlated with the diameter of preovulatory follicle during pre-ovulatory period $(\mathrm{r}=0.84$, $p<0.05$; Fig. 3). The plasma concentration of progesterone started to increase from Day $1(1.1 \pm 0.1 \mathrm{ng} / \mathrm{ml})$ and reached at the peak $(11.8 \pm 1.7 \mathrm{ng} / \mathrm{ml})$ on Day $9.0 \pm 0.1$. Thereafter, progesterone concentration remained constant for three days until Day 12 of ovulation. On an average, plasma progesterone concentration declined on Day 12.2 \pm 0.2 and reached at basal concentration $<2 \mathrm{ng} / \mathrm{ml}$ on Day 16.2 \pm 0.1 of the cycle (Fig. 2). Plasma profiles of progesterone 
during follicular and luteal phases are shown in (Table II) A positive correlation $(\mathrm{r}=0.93, p<0.05)$ between plasma progesterone concentration and diameter of CL was observed during the estrous cycle (Fig. 2).

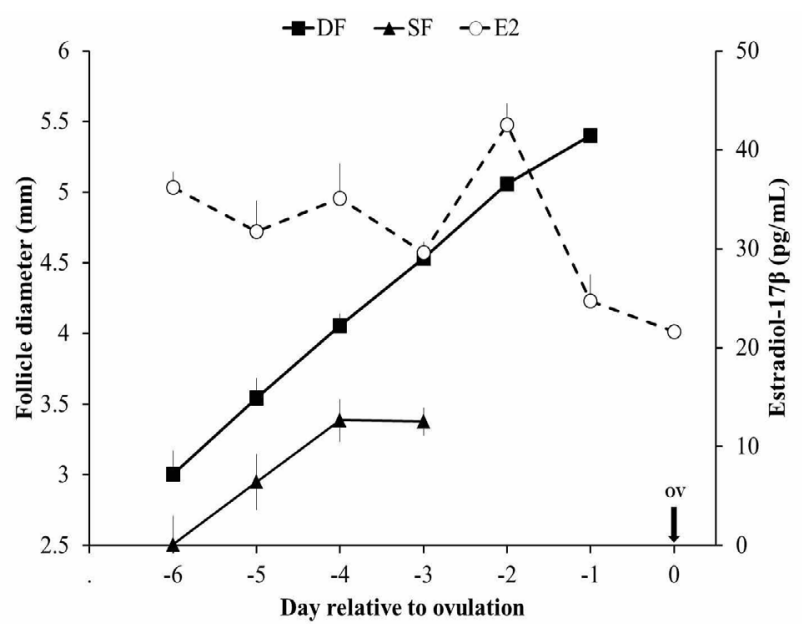

Fig. 3. Relationship of the largest follicle (F1) and subordinate (SF) follicle (diameter; mean \pm SEM) with that of plasma estradiol-17 $\beta$ concentration $\left(\mathrm{E}_{2}\right)$ during the preovulatory period in Lohi sheep. The plasma E2 increased with the diameter of preovulatory follicles $(\mathrm{r}=$ $0.84 ; p<0.05)$ and reached at maximum concentration $48 \mathrm{~h}$ before ovulation.
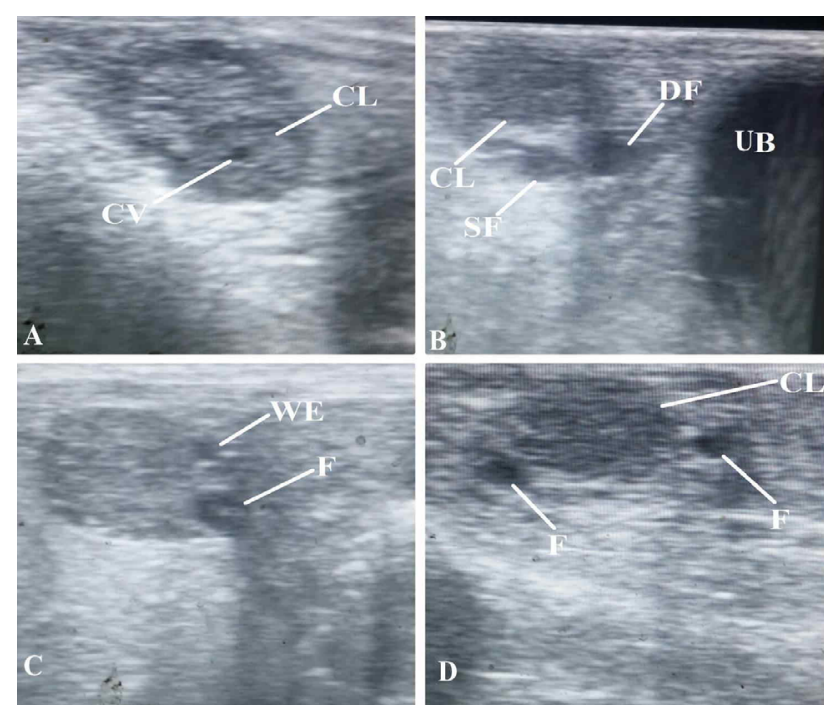

Fig. 4. Representative ovarian ultrasound images of Lohi sheep. A) Ovary having a corpus luteum (CL) with cavity (CV). B) Ovary detected cranial to the urinary bladder (UB) showing a CL, dominant follicle (DF), and a subordinate follicle (SF). C) Ovary having multiple small follicles (F) at the time of follicular wave emergence (WE). D) Ovary showing mid-luteal phase CL and follicles (F).

\section{DISCUSSION}

In the current study, growth pattern of ovarian follicles in Lohi sheep was similar to other sheep breeds i.e., 3- or 4-waves during the estrous cycle (Bartlewski et al., 2011). Nevertheless, the follicular wave pattern varies from 3 to 6 waves (Noel et al., 1993; Ginther et al., 1995) in different sheep breeds, Lohi sheep showed a predominant 3-wave pattern. Consequently, the statistical comparison for the 4-wave cycles could not be made in the current study due to limited observations. The IOI in Lohi sheep ranged between 16-18 days and was ostensibly independent of the follicular wave pattern. Previously, it has been documented that the estrous cycle in sheep may vary for 1-2 days irrespective of follicular wave pattern (Goodman, 1994; Bartlewski et al., 1999). It has been suggested that repeatability of a wave pattern within an animal may be associated with nutritional plane or season of the year, but the exact mechanism is unknown.

In comparison with other sheep breeds (Ginther et al., 1995; Bartlewski et al., 2011), time of wave emergence in Lohi sheep varied by $24 \mathrm{~h}$ and may be related to the fluctuation in the rise of FSH prior to wave emergence (Souza et al., 1998; Bister et al., 1999). Similarly, the average diameters of preovulatory follicles in various sheep breeds varied from 5 to $7 \mathrm{~mm}$ (Ali et al., 2006), Lohi sheep had a relatively smaller diameter of ovulatory follicles; suggesting that it could be a breed specific character. Analogues to ovulation rate in other sheep breeds (Noel et al., 1993; Bartlewski et al., 1999), Lohi sheep had predominantly single ovulation; however, occasional multiple births have also been reported in Lohi sheep (Ahmad et al., 2001) which may be associated with live weight and breeding season of ewes.

The longer interwave interval between ovulatory and first wave (W3-W1) in Lohi sheep was similar to the Western White Face sheep (Toosi et al., 2009) but was contrary to that of Beetal goat (Murtaza et al., 2019). It appears that Lohi sheep has early emergence of the ovulatory wave during the follicular phase and shorter duration of the other follicular waves. Consequently, F1 of the ovulatory wave had prolonged dominance phase and a larger diameter than the F1 of other waves. A likely reason for such an extended period of dominance of ovulatory follicle may be the slow decline of progesterone concentration (Toosi et al., 2009). On the other hand, the shorter dominance of F1 of waves 1 and 2 of Lohi sheep could be due to rising concentration of plasma progesterone during luteal phase (Toosi et al., 2009). In corroboration, progesterone concentration in Lohi sheep during follicular phase declined slowly and increased quickly after the ovulation. Nevertheless, the dominant follicle of ovulatory wave was larger than those of other 
waves in Lohi sheep, and corresponded well with studies in sheep (Seekallu et al., 2010) and goats (Nogueira et al., 2015; Murtaza et al., 2019).

In the current study, estradiol-17 $\beta$ concentration in Lohi ewes was associated with the diameter of the largest follicle, and interval to ovulation after preovulatory estradiol-17 $\beta$ peak was similar to that of other sheep breeds (Bartlewski et al., 1999). Although the multiple low peaks of estradiol-17 $\beta$ did not have a distinct pattern during the estrous cycle of Lohi sheep but they appeared to be associated with the dominant follicle of each wave, and resembled with the estradiol-17 $\beta$ pattern of other sheep breeds (Rawlings and Cook, 1993).

The relationship between $\mathrm{CL}$ diameter and progesterone concentration in Lohi sheep was indicative of plasma progesterone index. Maximum mean plasma progesterone concentration during luteal phase was achieved earlier in Lohi sheep than other sheep breeds i.e., 9 vs. 11 days post-ovulation, respectively (ContrerasSolis et al., 2008; Baby and Bartlewski, 2011; Bartlewski et al., 2011). Likewise, after the luteolysis, progesterone concentration declined $24 \mathrm{~h}$ earlier in Lohi sheep than other sheep breeds i.e., Day 12 vs. Day 13, respectively (Bartlewski et al., 1999). Concurrently, the physiological and morphological demise of CL also began from Day 12 onwards in Lohi sheep. However, CL remained detectable via ultrasounds even though progesterone reached nadir $(<2 \mathrm{ng} / \mathrm{ml})$ by Day 16 of the cycle as described in other sheep breeds (Bartlewski et al., 1999).

\section{CONCLUSIONS}

The current study concludes that the Lohi sheep exhibited a wave-like pattern of follicular development and the majority of cycles were of 3-waves pattern. No obvious differences existed in follicular characteristics and endocrine profile of 3- or 4-wave cycles. In future, the studies could be conducted to understand the mechanism of selection of dominant follicles to elucidate the factors associated with increasing the number and diameter of ovulatory follicles in Lohi sheep.

\section{Statement of conflict of interest}

Authors declare no conflict of interests and have no financial or personal relationship(s) which may have inappropriately influenced the research and the write-up of this paper.

\section{REFRENCES}

Ahmad, Z., Yaqoob, M. and Younas, M., 2001. The lohi sheep: A meat breed of Pakistan-review. Pak. J.
Agric., 38: 69-72.

Ali, A., Derar, R. and Hussein, H., 2006. Seasonal variation of the ovarian follicular dynamics and luteal functions of sheep in the subtropics. Theriogenology, 66: 463-469. https://doi. org/10.1016/j.theriogenology.2005.12.010

Babar, M., Ahmad, Z., Nadeem, A. and Yaqoob, M., 2004. Environmental factors affecting birth weight in lohi sheep. Pak. Vet. J. , 24: 5-8.

Babar, M.E., 1994. Genetics and phenotypic parameters of some performance characteristics of Lohi sheep. University of Agriculture Faisalabad.

Baby, T.E., and Bartlewski, P.M., 2011. Circulating concentrations of ovarian steroids and folliclestimulating hormone (FSH) in ewes with 3 or 4 waves of antral follicle emergence per estrous cycle. Reprod. Biol., 11: 19-36. https://doi.org/10.1016/ S1642-431X(12)60061-8

Bartlewski, P., Beard, A., Cook, S., Chandolia, R., Honaramooz, A. and Rawlings, N., 1999. Ovarian antral follicular dynamics and their relationships with endocrine variables throughout the oestrous cycle in breeds of sheep differing in prolificacy. Reproduction, 115: 111-124. https://doi. org/10.1530/jrf.0.1150111

Bartlewski, P., Beard, A. and Rawlings, N., 1999. The relationship between vaginal mucous impedance and serum concentrations of estradiol and progesterone throughout the sheep estrous cycle. Theriogenology, 51: 813-827. https://doi. org/10.1016/S0093-691X(99)00029-1

Bartlewski, P., Beard, A. and Rawlings, N., 1999. An ultrasonographic study of luteal function in breeds of sheep with different ovulation rates. Theriogenology, 52: 115-130. https://doi. org/10.1016/S0093-691X(99)00114-4

Bartlewski, P.M., Baby, T.E. and Giffin, J.L., 2011. Reproductive cycles in sheep. Anim. Reprod. Sci., 124: 259-268. https://doi.org/10.1016/j. anireprosci.2011.02.024

Bister, J.-L., Noel, B., Perrad, B., Mandiki, S., Mbayahaga, J. and Paquay, R., 1999. Control of ovarian follicles activity in the ewe. Domest. Anim. Endocrinol., 17: 315-328. https://doi.org/10.1016/ S0739-7240(99)00047-8

Boscos, C., Samartzi, F., Dellis, S., Rogge, A., Stefanakis, A. and Krambovitis, E., 2002. Use of progestagengonadotrophin treatments in estrus synchronization of sheep. Theriogenology, 58: 1261-1272. https:// doi.org/10.1016/S0093-691X(02)01040-3

Campbell, B.K., Scaramuzzi, R. and Webb, R., 1995. Control of antral follicle development and selection 
in sheep and cattle. J. Reprod. Fertil. Suppl., 49: 335-350.

Contreras-Solis, I., Diaz, T., Lopez, G., Caigua, A., Lopez-Sebastian, A. and Gonzalez-Bulnes, A., 2008. Systemic and intraovarian effects of corpus luteum on follicular dynamics during estrous cycle in hair breed sheep. Anim. Reprod. Sci., 104: 47-55. https://doi.org/10.1016/j.anireprosci.2007.01.021

Economic Survey of Pakistan, 2018-2019. GOP, Finance Division, Pakistan.

Ginther, O., Gastal, E., Gastal, M., Bergfelt, D., Baerwald, A. and Pierson, R., 2004. Comparative study of the dynamics of follicular waves in mares and women. Biol. Reprod., 71: 1195-1201. https:// doi.org/10.1095/biolreprod.104.031054

Ginther, O., Kot, K. and Wiltbank, M., 1995. Associations between emergence of follicular waves and fluctuations in fsh concentrations during the estrous cycle in ewes. Theriogenology, 43: 689-703. https://doi.org/10.1016/0093691X(94)00074-5

Goodman, R., 1994. Neuroendocrine control of the ovine estrous cycle. Physiol. Reprod., 2: 659-710.

Khan, M.A., 2002. Reproductive efficiency of farm animals in the tropics. Animal Agriculture Bureau (AAB). Rawalpindi, Pakistan.

Murtaza, A., Ahmad, W., Sohail, T., Khan, M.I.u.R., Mohsin, I., Shahzad, M., Hussain, M., Tahir, M.Z. and Ijaz, M., 2019. Follicular dynamics and changes in oestradiol-17 $\beta$, progesterone and $\mathrm{Lh}$ profiles following $\mathrm{PGF}_{2 \alpha}$ induced oestrus in early and late ovulating beetal goats. Reprod. Domest. Anim., 54: 545-550. https://doi.org/10.1111/rda.13392

Murtaza, A., Khan, M.I.-u.-R., Ahmad, W., Sohail, T., Mohsin, I., Shahzad, M., Tahir, M.Z. and Ijaz, M., 2019. Follicular dynamics and changes in plasma estradiol-17 $\beta$ and progesterone concentrations during estrous cycle in beetal goats. Pak. Vet. J., 39: 193-198. https://doi.org/10.29261/ pakvetj/2019.046

Neal, S.F., Surface, R.A., Pritchard, J.Y., Dailey, R.A., Townsend, E.C. and Inskeep, K.E., 1993. Ovarian structures during the estrous cycle and early pregnancy in ewes. Biol. Reprod., 49: 1133-1140. https://doi.org/10.1095/biolreprod49.5.1133

Noel, B., Bister, J. and Paquay, R., 1993. Ovarian follicular dynamics in suffolk ewes at different periods of the year. Reproduction, 99: 695-700. https://doi.org/10.1530/jrf.0.0990695

Nogueira, D.M., Cavalieri, J., Gummow, B. and Parker, A., 2015. Comparison of follicular dynamics and hormone profiles in boer goats examined during the breeding and non-breeding seasons in the tropics of Queensland, Australia. Small Rumin. Res., 125: 93-100. https://doi.org/10.1016/j. smallrumres.2015.02.014

Rawlings, N. and Cook, S., 1993. LH secretion around the time of the preovulatory gonadotrophin surge in the ewe. Anim. Reprod. Sci., 30: 289-299. https:// doi.org/10.1016/0378-4320(93)90079-7

Seekallu, S., Toosi, B., Duggavathi, R., Barrett, D., Davies, K., Waldner, C. and Rawlings, N., 2010. Ovarian antral follicular dynamics in sheep revisited: Comparison among estrous cycles with three or four follicular waves. Theriogenology, 73: $\quad 670-680 . \quad \mathrm{https}: / /$ doi.org/10.1016/j. theriogenology.2009.11.007

Sirois, J. and Fortune, J., 1988. Ovarian follicular dynamics during the estrous cycle in heifers monitored by real-time uitrasonograph. Biol. Reprod., 39: 308-317. https://doi.org/10.1095/ biolreprod39.2.308

Souza, C., Campbell, B. and Baird, D., 1998. Follicular waves and concentrations of steroids and inhibin a in ovarian venous blood during the luteal phase of the oestrous cycle in ewes with an ovarian autotransplant. J. Endocrinol., 156: 563-572. https://doi.org/10.1677/joe.0.1560563

Titi, H., Kridli, R. and Alnimer, M., 2010. Estrus synchronization in sheep and goats using combinations of gnrh, progestagen and prostaglandin f $2 \alpha$. Reprod. Domest. Anim., 45: 594-599.

Toosi, B., Seekallu, S., Pierson, R. and Rawlings, N., 2009. Evaluation of the ultrasound image attributes of developing ovarian follicles in the four follicular waves of the interovulatory interval in ewes. Theriogenology, 72: 902-909. https://doi. org/10.1016/j.theriogenology.2009.06.006

Wildeus, S., 2000. Current concepts in synchronization of estrus: Sheep and goats. $J$. Anim. Sci., 77: 1-14. https://doi.org/10.2527/ jas2000.00218812007700ES0040x 